\title{
Chlorophyll fluorescence imaging can reflect development of vascular connection in grafting union in some Solanaceae species
}

\author{
C. PENELLA*, A. PINA ${ }^{* *}$, A. SAN BAUTISTA ${ }^{* * *}$, S. LÓPEZ-GALARZA ${ }^{* * *}$ and Á. CALATAYUD ${ }^{*++}$ \\ Instituto Valenciano de Investigaciones Agrarias (IVIA). Departamento de Horticultura, Valencia, Spain* \\ Centro de Investigación y Tecnología Agroalimentaria de Aragón, Unidad de Hortofruticultura, Zaragoza, Spain** \\ Universitat Politècnica de València. Departamento de Producción Vegetal, Valencia, Spain ${ }^{* * *}$
}

\begin{abstract}
Graft union development in plants has been studied mainly by destructive methods such as histological studies. The aim of this work was to evaluate whether the chlorophyll fluorescence imaging (CFI) technique is sensitive enough to reflect changes at the cellular level in different Solanaceae grafted plants $30 \mathrm{~d}$ after grafting, when both grafted partners were well fused and strong enough in all plant combinations. The pepper cultivar 'Adige' was grafted onto different Capsicum spp. accessions typified with different compatibility degrees; eggplant was grafted on Solanum torvum and pepper homografts as compatible unions; pepper was grafted on S. torvum and on tomato as incompatible unions. 'Adige'/'Adige' and 'Adige'/pepper A25 showed a higher maximum quantum efficiency of PSII associated with higher values of actual quantum efficiency of PSII and photochemical quenching as well as with vascular regeneration across the graft interface. Our results highlighted that CFI changes reflected histological observations in grafted Solanaceae plants.
\end{abstract}

Additional key words: callus; compatibility; graft; pepper, photochemical quenching; vascular connections.

\section{Introduction}

Grafting can be defined as a natural or deliberate fusion of plant parts in a way that vascular continuity is established between them and the resulting genetically composite organism functions as a single plant (Mudge et al. 2009). Grafting is a technique that has been widely used for centuries in woody plants. Nowadays, this technique is being greatly expanding into vegetable plants, particularly in Solanaceae and Cucurbitaceae families, in order to reduce pathogen infections (Biles et al. 1989, Padgett and Morrison 1990) or to increase resistance to abiotic stresses, such as drought (Sánchez-Rodríguez et al. 2013, Penella et al. 2014a), salinity (Orsini et al. 2013, Penella et al. 2015), or heavy metals (Savvas et al. 2010). This is also used to enhance nutrient uptake (Ruiz et al. 1997) or to increase yields and fruit quality (Rouphael et al. 2010, Penella et al. 2013).

During the graft union formation between rootstock and scion, many researchers have observed callus proliferation (from both the rootstock and scion), callus bridge formation, differentiation of cambium tissue from callus cells, and the production of secondary xylem and phloem (Hartmann et al. 2002, Pina and Errea 2005, Aloni et al. 2010, Trinchera et al. 2013). A low or improper callus formation between the rootstock and scion could lead to defoliation, reduction of scion growth, and low survival of grafted plants (Kawaguchi et al. 2008, Johkan et al. 2009) caused by reduction of water flow to shoots (decreased hydraulic conductance) (Martínez-Ballesta et al. 2010).

Received 6 September 2016, accepted 25 November 2016, published as online-first 8 February 2017.

${ }^{+}$Corresponding autor; Dr. Ángeles Calatayud, phone: +34 3424039, fax: +34 3424000, e-mail: calatayud ang@gva.es

Abbreviations: A - Capsicum annuum L. var. Adige; A25 - C. annuum accession A25; B14 - $\bar{C}$. baccatum accession B14; $\mathrm{C} 12$ - C. chinense accession C12; BEU - tomato rootstock Beufort; CFI - chlorophyll fluorescence imaging; Chl - chlorophyll; DAG - days after grafting; EGG - eggplant var. Cristal; $F_{m}$ - maximal fluorescence yield of the dark-adapted samples; $F_{m}{ }^{\prime}-$ maximal fluorescence yield of the light-adapted samples; $\mathrm{F}_{\mathrm{o}}$ - minimal fluorescence yield of the dark- adapted samples; $\mathrm{F}_{\mathrm{o}}{ }^{\text {- }}$ - minimal fluorescence yield of the light-adapted samples; $F_{s}-$ steady-state fluorescence yield during actinic irradiation; $F_{v}-$ variable fluorescence $\left(F_{m}-F_{o}\right)$ in the dark-adapted samples; $F_{v} / F_{m}$ - maximum quantum efficiency of PSII photochemistry; NPQ - nonphotochemical quenching calculated from Stern-Volmer equation; qP - photochemical quenching; ST - Solanum torvum; TOM - tomato var. Gordal;

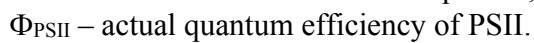

Acknowledgements: This work was financed by INIA (Spain) through Project RTA2013-00022-C02-01 and the European Regional Development Fund (ERDF). 
There is no precise definition of graft compatibility and it generally means the establishment of a successful graft union as well as extended survival and proper functioning of the composite rootstock-scion (Goldschmidt 2014). Graft incompatibility may be defined as failure to form a successful graft union. A lack or decrease in a number of differentiated vascular bundles, or the dysfunction of differentiated vascular bundles at the graft union has been reported to inhibit transport of nutrients to scion (Wang and Kollmann 1996, Schöning and Kollmann 1997). Characterization of incompatibility is not a simple process because graft combinations can initially unite with apparent success, but they gradually develop incompatibility symptoms with time, due to either a limited and/or not fully functional vascular reconnection between scion and rootstock at the graft interface, which causes the subsequent failure of the graft union (Errea et al. 1994, Errea et al. 2001) or the development of abnormal growth patterns (Kawaguchi et al. 2008).

The major causes implicated in graft incompatibility in Solanaceae crops are anatomical and/or biochemical reasons (Deloire and Hébant 1982, Ives et al. 2012). In severely incompatible grafted plants, such as pepper/ tomato or pepper/eggplant grafts, growth inhibition and high mortality was observed due to narrow and irregular xylem connections between scions and rootstocks; this was associated with a higher concentration of sugars and starch above rather than below the graft union (Kawaguchi et al. 2008). Elevated production of reactive oxygen species, decrease in antioxidant enzyme activities or increase in polyphenol metabolites are a well-documented facts in graft-incompatible combinations from different Solanaceae species (Deloire et al. 1982, Fernández-García et al. 2004a, Ives et al. 2012)

Pepper (Capsicum annuum) is grown in most countries of the world, with 1.93 million of ha cultivated area and is one of the most important crops in Mediterranean area. Grafted pepper plants are used to cope with biotic and abiotic stresses (Oka et al. 2004, Penella et al. 2014a, Penella et al. 2015). Peppers have been described as compatible only with other Capsicum species but not with all of them. In this sense, Otsuka (1957) reported that tomato/pepper or pepper/tomato graft combinations were completely incompatible because plant growth was severely suppressed, in contrast to other Solanaceae species, such as tomato or eggplant, which are able to be grafted onto different species within their own family (Deloire and Hébant 1982, Miguel et al. 2007, Kawaguchi et al. 2008, Ives et al. 2012).

The first methods used to predict graft incompatibility relied on external symptoms, such as swollen union, death

\section{Materials and methods}

Plant material and grafting: A total of nine combinations of plants were evaluated for a graft compatibility. A cultivar 'Adige' of Capsicum annuum L. (A; Lamuyo or decline in vegetative growth and vigour of the scion, and marked differences in growth of both scion and rootstock (Otsuka 1957). Afterwards, physiological and anatomical methods for the diagnosis of graft (in)compatibility have been developed, such as the measurement of peroxidase and catalase activity as the enzymes implicated in graft development (Fernandez-Garcia et al. 2004a), hormone contents (Yin et al. 2012), reactive oxygen species (ROS) production (Irisarri et al. 2015), accumulation of sugars (Kawaguchi et al. 2008), hydraulic root conductivity (Clearwater et al. 2004) or histological observations (Pina et al. 2012). However, all these methods are invasive and destructive, slow and/or most of them are meant to woody plants.

The use of X-ray tomography to visualize the 3D structure of the graft union (Milien et al. 2012) is a nondestructive method to evaluate internal structure in the graft area, but the potential impact of the ionizing effects of the X-rays on the living tissue can be negative as it has been demonstrated in a growth-inhibited Arabidopsis seedlings (Dhondt et al. 2010) and consequently has to be considered.

Another nondestructive method without effects on plant tissues and on the subsequent development of plants is the use of the chlorophyll (Chl) fluorescence imaging (CFI). CFI has been used to predict compatibility in grafted melon plants (Calatayud et al. 2013), and the use of images for monitoring fluorescence parameters allowed to visualize possible alterations in grafted plants (Quilliam et al. 2006, Calatayud et al. 2013). This could be an intuitive, quick, and noninvasive method providing detailed information on spatial and temporal heterogeneity for evaluating behaviour of grafted plants.

The aim of this work was to evaluate the potential of CFI in different Solanaceae plant combinations using positive controls (pepper grafted onto pepper) and negative controls (tomato/pepper and eggplant/pepper), connecting values of CFI parameters to histological observations in order to demonstrate whether CFI can reflect the morphological and anatomical changes at the graft interface between both grafted partners. In order to reach this objective, the commercial pepper cultivar 'Adige' was grafted on different Capsicum spp. accessions typified with different compatibility degree in terms of yield and quality found in previous works of this research group (Penella et al. 2013, 2014b,c, 2015). We also used different graft combinations with known graft compatibility as controls: eggplant grafted on S. torvum and pepper homografts (high compatibility), pepper grafted on S. torvum, and pepper grafted on tomato as incompatible unions.

type; Sakata Seeds, Japan), was grafted onto the accessions of C. annuum L. (A25 and A5), Capsicum chinense Jacq. (C12), Capsicum baccatum L. var. pendulum (B14), which 
were used in previous studies on physiological and agronomical responses and which showed different compatibility degree (Penella et al. 2013, Penella et al. 2014a, Penella et al. 2014c, Penella et al. 2015). In addition, two commercial rootstocks were used: Solanum torvum Sw. "Torvum vigor" (ST; Ramiro Arnedo, Spain) and L. esculentum x L. hirsutum "Beaufort" (BEU; De Ruiter Seeds, Nederland) described in as incompatible (Kawaguchi et al. 2008). Besides tomato var. Gordal (TOM; Mascarell Seeds, Spain) was grafted on ST $\mathrm{TOM} / \mathrm{ST}$; this combination has been described as moder- ately incompatible (Kawaguchi et al. 2008). Solanum melongena L. eggplant "Cristal” (EGG; Fitó Seeds, Spain) was also grafted onto ST - EGG/ST and selfgrafted plants of 'Adige'- A/A were used as positive controls.

Identification of the intra- or interspecific grafting is shown below for each plant combinations. Estimated affinity (according to literature and previous studies) is represented by $(++)$ - compatible, $(+)-$ moderately compatible, (-) - moderately incompatible, and (--) incompatible-grafted plant combinations.

\begin{tabular}{llll}
\hline Rootstock (code) & Scion & Graft plant & $\begin{array}{l}\text { Estimated } \\
\text { affinity }\end{array}$ \\
\hline Capsicum annuum L. var. Adige ( A) & Adige (A) & A/A (intraspecific) & ++ \\
C. annuum (A25) & Pepper var. Adige (A) & A/A25 (intraspecific) & ++ \\
C. annuum (A5) & Pepper var. Adige (A) & A/A5 (intraspecific) & - \\
C. baccatum (B14) & Pepper var. Adige (A) & A/B14 (intraspecific) & + \\
C. chinense (C12) & Pepper var. Adige (A) & A/C12 (interspecific) & + \\
S. torvum (ST) & Eggplant var. Cristal (EGG) & EGG/ST (interspecific) & ++ \\
S. torvum (ST) & Pepper var. Adige (A) & A/ST (interspecific) & -- \\
S. torvum (ST) & Tomato var. Gordal (TOM) & TOM/ST (interspecific) & - \\
Tomato Beaufort (BEU) & Adige (A) & A/BEU (interspecific) & -- \\
\hline
\end{tabular}

Plants were sown on 15 January 2014 in 104-cell polystyrene trays filled with peat-based substrate and kept under a Venlo-type glasshouse. The plants were transplanted to 54-cell trays. The different graft combinations were prepared on 21 March using the tube grafting method (cutting the growing tip of the rootstock at a $45^{\circ}$ angle above the cotyledons, and fixing the rootstock and scion with a clip) (Penella et al. 2013).

Ten days after grafting, only the compatible grafted plants were fused by about $75 \%$, the number of fused in these plants increased with time, reaching 98\% $20 \mathrm{~d}$ after grafting (DAG). In incompatible-grafted plants, both graft partners were fused later (30 DAG) and the percentage of fused grafts was low $30 \%$. For this reason, Chl fluorescence kinetic could not be done at earlier stages of development and all plants were measured at $30 \mathrm{DAG}$.

Light microscopy: The graft interfaces were fixed at $30 \mathrm{DAG}$ in $3 \%$ glutaraldehyde in $50 \mathrm{mM}$ Sorensen buffer

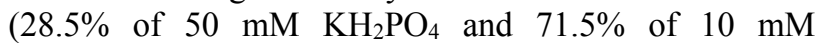
$\mathrm{Na}_{2} \mathrm{HPO}_{4}$ ) at $\mathrm{pH} 7.2$ for $2 \mathrm{~h}$. After that, plant material was washed four times during $15 \mathrm{~min}$ in the same buffer. After infiltration in different $L R$ White resin : ethanol ratios $(1: 2$ $\mathrm{v} / \mathrm{v}, 1: 1 \mathrm{v} / \mathrm{v}, 2: 1 \mathrm{v} / \mathrm{v})$ for $60 \mathrm{~min}$ per stage, the specimens were embedded in LR White resin overnight (London Resin Co., Woking, Surrey, UK) at $4^{\circ} \mathrm{C}$ according to Tadeo et al. (1997), and transversally sectioned at $2 \mu \mathrm{m}$ using glass knives in a Leica RM 2165 rotary microtome (Leica Instruments, Heidelberg, Germany). The sections were stained in $0.05 \%$ Toluidine blue 0 (Merck, Darmstad, Germany) (O’Brien and McCully 1981), desiccated and mounted in Eukitt Mounting Medium 15322 (Electron
Microscopy Sciences, Hatfield, PA, USA). Representative sections of three tissue samples per plant from ten plants were viewed under a Leitz Ortholux II fluorescence microscope (Leitz, Wetzal, Germany) operating in an optical mode and the images were captured with a Leica DC300 camera.

Chlorophyll (Chl) fluorescence imaging measurements of grafted plants were performed 30 DAG with 15-20 plants per combination on stems at $2 \mathrm{~cm}$ above and below the graft interface and the graft interface using an ImagingPAM fluorometer (Walz, Effeltrich, Germany). All plants were placed in the dark for 20 min prior to measurements. Images and values of minimum Chl fluorescence yield in the dark-adapted state, $F_{0}$, were determined using light pulses at low frequency $(1 \mathrm{~Hz})$. Maximum fluorescence $F_{m}$ was determined by applying a blue saturation pulse $(10 \mathrm{~Hz})$. The maximum quantum yield of PSII photochemistry $\left(\mathrm{F}_{\mathrm{v}} / \mathrm{F}_{\mathrm{m}}\right)$ was determined as $\left(\mathrm{F}_{\mathrm{m}}-\mathrm{F}_{\mathrm{o}}\right) / \mathrm{F}_{\mathrm{m}}$ and images were captured. Actinic illumination [260 $\mu \mathrm{mol}$ (photon) $\mathrm{m}^{-2} \mathrm{~s}^{-1}$ ] was then switched on and saturating pulses were applied at $20 \mathrm{~s}$ intervals for $5 \mathrm{~min}$ to determine $\mathrm{F}_{\mathrm{m}}{ }^{\prime}$ and $\mathrm{Chl}$ fluorescence kinetics during actinic illumination $\left(\mathrm{F}_{\mathrm{s}}\right)$. The actual quantum efficiency of PSII photochemistry $\left[\Phi_{\mathrm{PSII}}=\left(\mathrm{F}_{\mathrm{m}}{ }^{\prime}-\mathrm{F}_{\mathrm{s}}\right) / \mathrm{F}_{\mathrm{m}}{ }^{\prime}\right]($ Genty et al. 1989), photochemical quenching $\left[\mathrm{q}_{\mathrm{P}}=\left(\mathrm{F}_{\mathrm{m}}^{\prime}-\mathrm{F}_{\mathrm{s}}\right) /\left(\mathrm{F}_{\mathrm{m}}{ }^{\prime}-\mathrm{F}_{\mathrm{o}}{ }^{\prime}\right)\right]$ (Schreiber et al. 1986) and the nonphotochemical quenching $\left[\mathrm{NPQ}=\mathrm{F}_{\mathrm{m}}{ }^{\prime}-\mathrm{F}_{\mathrm{s}} / \mathrm{F}_{\mathrm{m}}{ }^{\prime}\right.$ ] (Bilger and Björkman 1991) were calculated. The value of $F_{0}{ }^{\prime}$ was estimated using the approximation of (Oxborough and Baker 1997), $\left[\mathrm{F}_{\mathrm{o}}{ }^{\prime}=\mathrm{F}_{\mathrm{o}} /\left(\mathrm{F}_{\mathrm{v}} / \mathrm{F}_{\mathrm{m}}+\mathrm{F}_{\mathrm{o}} / \mathrm{F}_{\mathrm{m}}{ }^{\prime}\right)\right]$. Three areas were defined through PAM-software in stem of the plants (graft area, the 
rootstock, and the scion). Fluorescence parameter values of all pixels within each area were averaged. Each value in the tables is the mean of the corresponding area of all samples (obtained from 15-20 different plants). The images shown here presented only a single plant (representative plant). Further information on CFI measurements can be obtained from Calatayud et al. (2008, 2013).

\section{Results and discussion}

Histological evaluation of scion/rootstock interactions: Pepper homografting (A/A) and the intraspecific grafts (rootstock and scion belonging to the same botanical species) of rootstocks B14, C12, and A25 showed a higher yield (Penella et al. 2014a, 2015) than the intraspecific combination 'Adige' grafted onto the rootstock A5 (A/A5). The A/A5 combination exhibited a slower growth than other grafted plants $(\mathrm{A} / \mathrm{B} 14, \mathrm{~A} / \mathrm{C} 12$, and $\mathrm{A} / \mathrm{A} 25)$ and its stem diameter at the graft union was approximately three-fold greater and provided lower fruit yields (Penella et al., 2013, Penella et al. 2014a).

The cellular events, which lead to a successful graft union, include adhesion of both graft partners, callus cell proliferation at the graft interface, and cross-bridge formation of the vascular bundles in order to establish a functional vascular connection (Pina and Errea 2005, Mudge et al. 2009, Aloni et al. 2010, Goldschmidt 2014). Nevertheless, incomplete or nonfunctional vascular connections impede vital upward and downward transfer routes through the whole plant, which might result in a death of the graft. By 30 DAG, a well developed vascular graft union was observed in the pepper homografts (A/A) and intraspecific heterografts of EGG/ST (Fig. 1A,B) and of $\mathrm{A} / \mathrm{A} 25$ and $\mathrm{A} / \mathrm{C} 12$ (Fig. $1 C, D$ ). In these combinations,
Statistical analysis: One-way analysis of variance (ANOVA) was performed (Statgraphics Centurion XVI for Windows, Statistical Graphics Corp.) to compare the means of the fluorescence parameters. Mean separations were performed when significant differences were found using the least significance difference at $P<0.05$.

most of the necrotic layer was absorbed at this stage and a group of small callus cells were clustering to resemble symplastic domains which is a prerequisite of starting further vascular differentiation (Pina et al. 2009). Higher levels of vascular differentiation were observed in A/A25 (Fig. 1C) than that in $\mathrm{A} / \mathrm{C} 12$ (Fig. 1D). In all combinations, cluster of callus cells were associated with the cut ends of the xylem from which they were derived and filled the graft interface. The A/B14 showed a high cellular activity at the graft interface and callus cells bridging both grafted partners (Fig. 1E). Some developing tracheid elements were observed, but not completely new xylem and phloem formation was displayed across the graft union at $30 \mathrm{DAG}$. Similar anatomical results were obtained with TOM/ST (combination of more distant taxonomic species, Fig. 1F), indicating that the compatibility behaviour of both graft combinations (A/B14 and TOM/ST) was similar, moderately compatible, as reported by Kawaguchi et al. (2008) for $\mathrm{TOM} / \mathrm{ST}$.

A stronger graft incompatibility was observed in A/A5. In this case, histological examination provided clear evidence of discontinuous xylem elements at the graft union as well as large areas of unbroken necrotic lines along the wounded edges of the rootstock and the scion
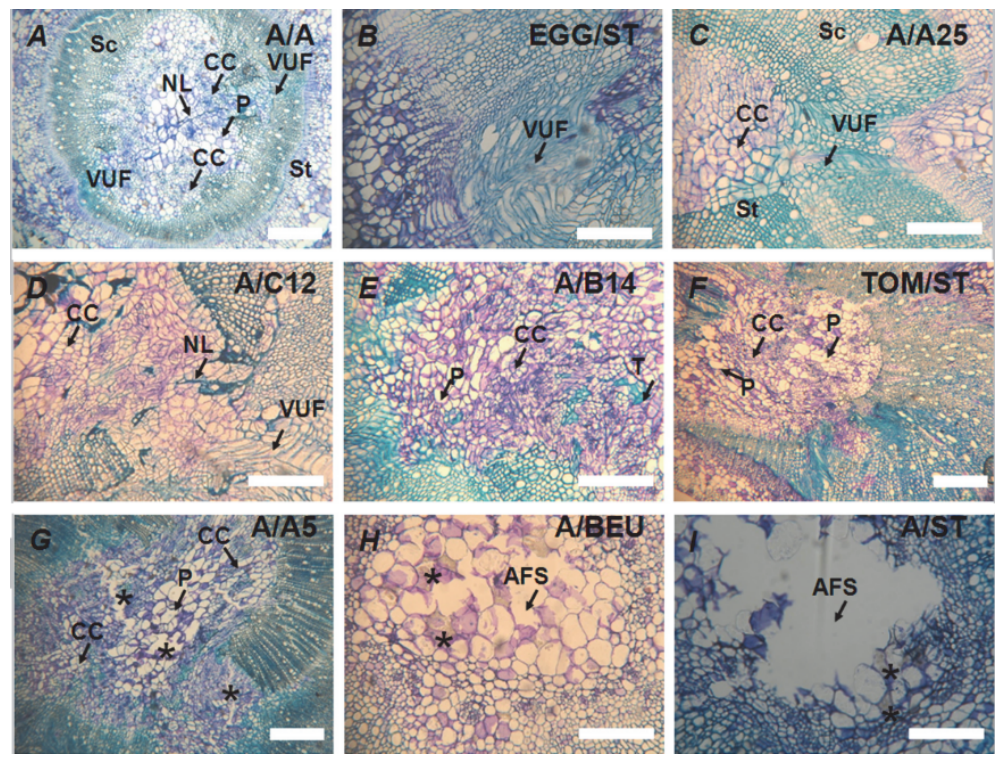

Fig. 1. Transversal sections of different graft combinations (see codes in text table in Materials and methods) 30 days after grafting. $A-\mathrm{A} / \mathrm{A}, B-$ EGG/ST, $C-\mathrm{A} / \mathrm{A} 25, D-\mathrm{A} / \mathrm{C} 12, E-\mathrm{A} / \mathrm{B} 14, F-$ $\mathrm{TOM} / \mathrm{ST}, G-\mathrm{A} / \mathrm{A} 5$, asterisks (*) show limited fusion between both graft. 
Table 1. Maximum quantum efficiency of PSII photochemistry $\left(\mathrm{F}_{\mathrm{v}} / \mathrm{F}_{\mathrm{m}}\right)$ in dark-adapted samples for different plant combinations at the areas of the rootstock, graft zone, and scion after 30 DAG. Values are the means for $n=15-20$ plant combinations. Different letters in columns indicate significant difference at $p \leq 0.05$ by using LSD test.

Plant combination $F_{v} / F_{m}$ rootstock $\quad F_{v} / F_{m}$ graft area $F_{v} / F_{m}$ scion

\begin{tabular}{llll}
\hline A/A & $0.760^{\mathrm{a}}$ & $0.746^{\mathrm{a}}$ & $0.760^{\mathrm{a}}$ \\
$\mathrm{A} / \mathrm{A} 25$ & $0.781^{\mathrm{a}}$ & $0.774^{\mathrm{a}}$ & $0.779^{\mathrm{a}}$ \\
$\mathrm{A} / \mathrm{B} 14$ & $0.791^{\mathrm{a}}$ & $0.770^{\mathrm{a}}$ & $0.774^{\mathrm{a}}$ \\
$\mathrm{A} / \mathrm{C} 12$ & $0.807^{\mathrm{a}}$ & $0.753^{\mathrm{a}}$ & $0.757^{\mathrm{a}}$ \\
$\mathrm{A} / \mathrm{A} 5$ & $0.754^{\mathrm{ab}}$ & $0.723^{\mathrm{b}}$ & $0.709^{\mathrm{b}}$ \\
EGG/ST & $0.782^{\mathrm{a}}$ & $0.770^{\mathrm{a}}$ & $0.760^{\mathrm{a}}$ \\
A/ST & $0.675^{\mathrm{c}}$ & $0.233^{\mathrm{d}}$ & $0.306^{\mathrm{d}}$ \\
TOM/ST & $0.788^{\mathrm{a}}$ & $0.769^{\mathrm{a}}$ & $0.757^{\mathrm{a}}$ \\
A/BEU & $0.713^{\mathrm{b}}$ & $0.633^{\mathrm{c}}$ & $0.453^{\mathrm{c}}$ \\
\hline
\end{tabular}

(Fig. 1G). This result was consistent with the anatomy of the severely incompatible union of A/BEU (Fig $1 H$ ). In addition, A/ST produced weak unions, characterized by limited fusion between both grafted partners (Fig. $1 I$ ) and the presence of cells enriched with green material inside the vacuoles similar to phenolic compounds, which are involved in the incompatibility reaction inhibiting division, development, and differentiation into new tissues during the graft union formation (Errea 1998, Pina et al. 2012, Hudina et al. 2014).

In the combinations of $\mathrm{A} / \mathrm{A} 5, \mathrm{~A} / \mathrm{BEU}$, and $\mathrm{A} / \mathrm{ST}$, the rootstock and scion tissue produced new vascular elements as well, but these did not cross the scion/rootstock border and therefore no graft union was formed. In incompatible heterografts between Arabidopsis grafted on tomato rootstock, it was reported that the remaining necrotic layer, which developed at the graft interface, seemed to inhibit the differentiation of vascular tissue across the graft union, either directly or indirectly, and thus prevented full vascular graft union formation between the two plants, since neither vascular bridge nor full graft union was visible (Flaishman et al. 2008). Other studies also reported the presence of narrow and irregular xylem elements in incompatible tomato/pepper heterografts (Kawaguchi et al. 2008, Ives et al. 2012).

Chl fluorescence imaging in grafted plants: The same grafted plants combinations used for histological evaluation were analysed by CFI.

The $F_{v} / F_{m}$ ratio is often used as an indicator of plant stress (Rolfe and Scholes 2010) and reflects the maximal efficiency of excitation capture in dark-adapted plants and is correlated with the number of functional PSII reaction centres (Oquist and Chow 1992) (Table 1). Concerning the $\mathrm{F}_{\mathrm{v}} / \mathrm{F}_{\mathrm{m}}$ values at the rootstock area, four groups of grafted plants were distinguished according to $A N O V A$ analysis: $\mathrm{A} / \mathrm{A}, \mathrm{A} / \mathrm{A} 25, \mathrm{~A} / \mathrm{B} 14, \mathrm{~A} / \mathrm{C} 12, \mathrm{TOM} / \mathrm{ST}$, and EGG/ST showed the higher $\mathrm{F}_{\mathrm{v}} / \mathrm{F}_{\mathrm{m}}$ values, $\mathrm{A} / \mathrm{A} 5$ exhibited the intermediate value, followed by $\mathrm{A} / \mathrm{BEU}$, and $\mathrm{A} / \mathrm{ST}$ showed the lower $F_{v} / F_{m}$ value. In compatible tomato grafted plants, structure of graft union showed formation of xylem and phloem vessels through the graft union at 8 DAG (Fernández-García et al. 2004b). But narrow and irregular connections were observed in a graft union between incompatible grafted plants, such as tomato/pepper or pepper/tomato three weeks after grafting (Kawaguchi et al. 2008). CFI measurements were performed at $30 \mathrm{DAG}$, therefore the anatomical symptoms associated with the graft (in)-compatibility were already internally manifested. The lower $F_{v} / F_{m}$ ratio in rootstock areas was measured in incompatible heterografts of $\mathrm{A} / \mathrm{BEU}$ and A/ST. As reported by the histological study, a weak graft connection occurred in these plants combinations, in such a way that it was expected that the translocation of assimilates from the scion to the rootstock resulted in a higher carbohydrate concentration in the scion part and lower concentration in the rootstocks (Kawaguchi et al. 2008). A limited assimilate supply to the rootstocks could reduce the size of root system and decrease metabolic activity with increasing damage to the photosynthetic apparatus and decreasing $\mathrm{F}_{\mathrm{v}} / \mathrm{F}_{\mathrm{m}}$ in rootstock area. Likewise, the $F_{v} / F_{m}$ values in the graft area followed the same tendency showed by the rootstock area, but the values underwent an important decline in the incompatible grafts of $\mathrm{A} / \mathrm{ST}$ and $\mathrm{A} / \mathrm{BEU}$. It was probably a consequence of a weak connection in rootstocks ( $S$. torvum and tomato). A low or incorrect callus formation led to a bad vascular connection at the rootstock-scion graft interface affecting water and nutrient translocation that can alter the photosynthesis in the graft zone (Martínez-Ballesta et al. 2010). For this reason, the $F_{v} / F_{m}$ values of the scion partners decreased to a greater extent compared to the rootstock values. These insufficient connections of vascular bundles were reflected in the scion part by the lowest $\mathrm{F}_{\mathrm{v}} / \mathrm{F}_{\mathrm{m}}$ values in A/ST and A/BEU (Table 1). $\mathrm{F}_{\mathrm{v}} / \mathrm{F}_{\mathrm{m}}$ images of representative samples (Fig. 2) allowed visualize the rootstock, graft, and scion areas, indicating that the technique was able to display large areas of the graft zone. The observation of color changes (ranging from black (0.000) to pink (1.000) revealed spatial changes in the $\mathrm{F}_{\mathrm{v}} / \mathrm{F}_{\mathrm{m}}$ images. In $\mathrm{A} / \mathrm{A}, \mathrm{A} / \mathrm{A} 25, \mathrm{~A} / \mathrm{B} 14, \mathrm{~A} / \mathrm{C} 12$, $\mathrm{TOM} / \mathrm{ST}$, and $\mathrm{EGG} / \mathrm{ST}$, different intensities of blue colors were observed associated with the higher values of $\mathrm{F}_{\mathrm{v}} / \mathrm{F}_{\mathrm{m}}$. In A/A5, a black line was observed across graft area-scion indicating a null $\mathrm{F}_{\mathrm{v}} / \mathrm{F}_{\mathrm{m}}$ values. A dramatic change in color from blue-green and brown of $\mathrm{F}_{\mathrm{v}} / \mathrm{F}_{\mathrm{m}}$ were observed in $\mathrm{A} / \mathrm{ST}$ and $\mathrm{A} / \mathrm{BEU}$, corresponding to the lower $\mathrm{F}_{\mathrm{v}} / \mathrm{F}_{\mathrm{m}}$ values. It should be noted that the scion area in $\mathrm{A} / \mathrm{ST}$ and $\mathrm{A} / \mathrm{BEU}$ showed the colors of green and brown associated with the lowest $F_{v} / F_{m}$ values.

When the $F_{v} / F_{m}$ values were compared at the scion part 

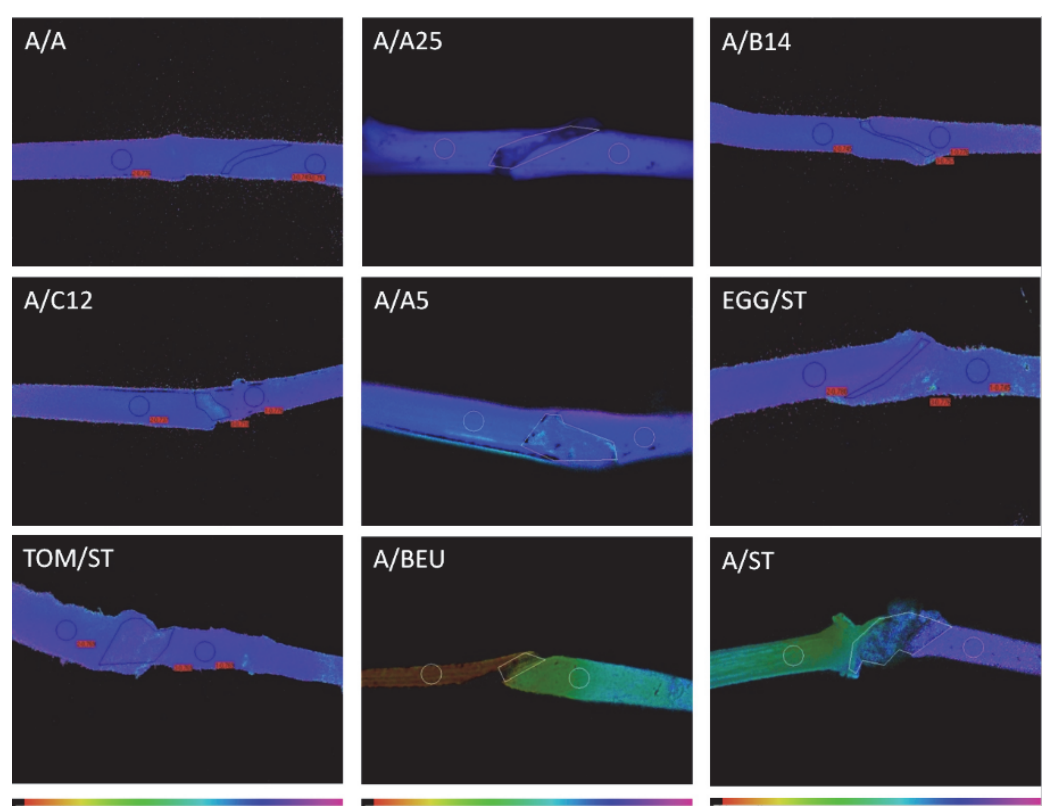

Fig. 2. Chlorophyll fluorescence images of maximum quantum efficiency of PSII photochemistry $\left(\mathrm{F}_{\mathrm{v}} / \mathrm{F}_{\mathrm{m}}\right)$ in dark-adapted samples after $30 \mathrm{DAG}$ in different plant combinations (see codes in Table 1): A/A, A/A25, A/B14, A/C12, A/A5, EGG/ST, $\mathrm{TOM} / \mathrm{ST}, \mathrm{A} / \mathrm{ST}$, and A/BEU. The false colour code depicted at the bottom of each image ranges from 0.000 - black to 1.000 - pink. Images were taken from a single representative plant.
Table 2. Effect of grafting on different plant combinationsin chlorophyll fluorescence parameters in light-adapted samples: actual quantum efficiency of PSII (ФPSII), photochemical quenching (qP) and nonphotochemical quenching (NPQ) in the scion area after 30 DAG. Values are the means for $n=15-20$ plant combinations. Different letters in columns indicate significant difference at $p \leq 0.05$ by using LSD test.

\begin{tabular}{llll}
\hline Plant combination & $\Phi_{\text {PSII }}$ & qP & NPQ \\
\hline A/A & $0.299^{\mathrm{a}}$ & $0.511^{\mathrm{a}}$ & $0.357^{\mathrm{b}}$ \\
$\mathrm{A} / \mathrm{A} 25$ & $0.346^{\mathrm{a}}$ & $0.541^{\mathrm{a}}$ & $0.268^{\mathrm{c}}$ \\
$\mathrm{A} / \mathrm{B} 14$ & $0.200^{\mathrm{ab}}$ & $0.322^{\mathrm{ab}}$ & $0.470^{\mathrm{a}}$ \\
$\mathrm{A} / \mathrm{C} 12$ & $0.175^{\mathrm{ab}}$ & $0.347^{\mathrm{ab}}$ & $0.536^{\mathrm{a}}$ \\
$\mathrm{A} / \mathrm{A} 5$ & $0.120^{\mathrm{b}}$ & $0.250^{\mathrm{b}}$ & $0.171^{\mathrm{d}}$ \\
EGG/ST & $0.298^{\mathrm{a}}$ & $0.496^{\mathrm{a}}$ & $0.290^{\mathrm{bc}}$ \\
A/ST & $0.097^{\mathrm{c}}$ & $0.179^{\mathrm{c}}$ & $0.087^{\mathrm{e}}$ \\
TOM/ST & $0.191^{\mathrm{ab}}$ & $0.336^{\mathrm{ab}}$ & $0.485^{\mathrm{a}}$ \\
A/BEU & $0.073^{\mathrm{c}}$ & $0.157^{\mathrm{c}}$ & $0.085^{\mathrm{e}}$ \\
\hline
\end{tabular}

in the different graft unions, the decrease in incompatible unions were more marked. Four categories could be well defined: compatible (A/A, A/A25, A/B14, A/C12, $\mathrm{TOM} / \mathrm{ST}$, and EGG/ST), moderate compatible (A/A5), incompatible (A/TOM), and strong incompatible plants (A/ST). If the weak graft connection occurred in A/A5, $\mathrm{A} / \mathrm{TOM}$, and A/ST, the probability of nutrient uptake reaching the scion decreased, leading to alteration in PSII photochemistry (Calatayud et al. 2013). In order to study the cause of this noticeable decline in $\mathrm{F}_{\mathrm{v}} / \mathrm{F}_{\mathrm{m}}$ at the scion area, we analysed their photochemical and nonphotochemical processes (Table 2). Statistical analysis of photochemical processes allowed differentiation into four groups: A/A, A/A25, and EGG/ST with higher values of $\Phi_{\text {PSII }}$ and $\mathrm{q}_{\mathrm{P}} ; \mathrm{A} / \mathrm{B} 14, \mathrm{~A} / \mathrm{C} 12$, and TOM/ST with moderate decline in photochemical processes; A/A5 with considerable decrease, and A/ST and A/BEU with the lowest photochemical efficiency. The decrease of $F_{v} / F_{m}$ in $A / A 5$,
$\mathrm{A} / \mathrm{BEU}$, and A/ST (Table 1) could be a result of an increase in protective nonradiative energy dissipation, photodamage of PSII centres or both (Osmond 1994). Inasmuch NPQ is believed to indicate the capacity for photoprotective processes (Osmond 1994), the decline in $\mathrm{F}_{\mathrm{v}} / \mathrm{F}_{\mathrm{m}}$ ratio was attributable to PSII stress, because NPQ was adversely affected in scion areas for above plant combinations (Table 2). NPQ values strongly decreased in severely damaged tissues (Berger et al. 2007). In addition, the lower qp values (Table 2) observed in $\mathrm{A} / \mathrm{A} 5, \mathrm{~A} / \mathrm{BEU}$, and $\mathrm{A} / \mathrm{ST}$ indicated that their capacity for reoxidizing $\mathrm{Q}_{\mathrm{A}}$ decreased, excitation pressure on PSII increased and contributed to the closure of PSII reaction centres. According to this result, $\Phi_{\text {PSII }}$ correlated with the quantum yield of noncyclic electron transport (Genty et al. 1989), and was markedly reduced mainly in A/ST and A/BEU (Table 2). This reflected that a low or incorrect callus formation (Fig. 1) affected vascular connection in the rootstock/scion interface and might determine a decrease in water and nutrient translocation (Martínez-Ballesta et al. 2010) affecting photosynthesis performance and limiting the availability of assimilates for plant growth.

In compatible and moderately compatible grafted plants of A/A, A/A25, A/B14, A/C12, TOM/ST, and EGG/ST, a higher $\Phi_{\mathrm{PSII}}$ and $\mathrm{q}_{\mathrm{P}}$ in the scion area was observed. This increase in photochemical process in the scion could support the formation of new connections at the graft interface. Associated with the stimulated electron flow $\left(\Phi_{\mathrm{PSII}}\right)$, NPQ increased as a protection mechanism in these graft combinations (Berger et al. 2007, Guidi et al. 2007).

Links between CFI parameters and histological studies: CFI supported the histological observations in our nine plant combinations. The statistical groups for $\Phi_{\mathrm{PSII}}$ at the scion area reflected better the histological observations indicating that $\mathrm{A} / \mathrm{A}, \mathrm{A} / \mathrm{A} 25$, and $\mathrm{EGG} / \mathrm{ST}$ with the highest 
values of this photochemical parameter showed wellformed vascular graft union with necrotic layer absorbed and a group of small callus cells, which were clustered resembling symplastic domains, a prerequisite to begin further vascular differentiation. The group of A/B14, $\mathrm{A} / \mathrm{C} 12$, and $\mathrm{TOM} / \mathrm{ST}$ with the moderate reduction in photochemical processes expressed the well-developed vascular graft union, but with less vascular differentiation than that found in the first group. Likewise, a strong correlation was observed between a considerable decrease in $\Phi_{\text {PSII }}$ and the presence of discontinuous xylem elements in the graft union of A/A5, as well as large areas of unbroken necrotic lines along the wounded edges of the rootstock and scion. The remaining combinations, A/ST and $\mathrm{A} / \mathrm{BEU}$, with the lowest photochemical values, formed weak unions, characterized by limited fusion between both graft partners and the presence of cells enriched with green material inside the vacuoles similar to phenolic compounds, which are involved in the incompatibility reaction

\section{References}

Aloni B., Cohen R., Karni L. et al.: Hormonal signaling in rootstock-scion interactions. - Sci. Hortic.-Amsterdam 127: 119-126, 2010.

Berger S., Benediktyová Z., Matouš K. et al.: Visualization of dynamics of plant-pathogen interaction by novel combination of chlorophyll fluorescence imaging and statistical analysis: differential effects of virulent and avirulent strains of $P$. syringae and of oxylipins on A. thaliana. - J. Exp.Bot. 58: 797806, 2007.

Biles C., Martyn R., Wilson H.: Isoenzymes and general proteins from various watermelon cultivars and tissue types. - HortSci. 24: 810-812, 1989.

Bilger W., Björkman O.: Temperature dependence of violaxanthin de-epoxidation and non-photochemical fluorescence quenching in intact leaves of Gossypium hirsutum L. and Malva parviflora L. - Planta 184: 226-234, 1991.

Calatayud Á., Gorbe E., Roca D., Martínez P.F.: Effect of two nutrient solution temperatures on nitrate uptake, nitrate reductase activity, $\mathrm{NH}_{4}{ }^{+}$concentration and chlorophyll a fluorescence in rose plants. - Environ. Exp. Bot. 64: 65-74, 2008.

Calatayud Á., San Bautista A., Pascual B. et al.: Use of chlorophyll fluorescence imaging as diagnostic technique to predict compatibility in melon graft. - Sci. Hortic.-Amsterdam 149: 13-18, 2013.

Clearwater M.J., Lowe R.G., Hofstee B.J. et al.: Hydraulic conductance and rootstock effects in grafted vines of kiwifruit. - J. Exp. Bot. 55: 1371-1382, 2004.

Deloire A., Hébant C.: Peroxidase activity and lignification at the interface between stock and scion of compatible and incompatible grafts of Capsicum on Lycopersicum. - Ann. Bot.-London 49: 887-891, 1982.

Dhondt S., Vanhaeren H., Van Loo D. et al.: Plant structure visualization by high-resolution X-ray computed tomography. - Trends Plant Sci. 15: 419-422, 2010.

Errea P., Garay L., Marín J.A.: Early detection of graft incompatibility in apricot (Prunus armeniaca) using in vitro techniques. - Physiol. Plantarum 112: 135-141, 2001. inhibiting division, development, and differentiation into new tissues during the graft union formation (Errea 1998).

Conclusion: This study represented the changes in CFI that might be useful as a reflection and/or concomitant of histological changes in grafted Solanaceae plants. In general terms, CFI provided information on a graft stage and represented a quick, noninvasive technique, which does not require sample preparation for studying such unions in vegetables. The main interest of CFI methods was associated with the images that permit large areas of graft zones to be viewed on the same plant. However, CFI cannot replace classical histology in terms of understanding morphological and anatomical developments at the graft interface. CFI could represent a high-throughput phenotyping tool necessary in order to reduce the time invested for determining behaviour of grafted plants and could be used as a sensor for detection of graft compatibility.

Errea P.: Implications of phenolic compounds in graft incompatibility in fruit tree species. - Sci. Hortic.-Amsterdam 74: 195205, 1998.

Errea P., Felipe A., Herrero M.: Graft establishment between compatible and incompatible Prunus spp. - J. Exp. Bot. 45: 393-401, 1994.

Fernández-García N., Carvajal M., Olmos E.: Graft union formation in tomato plants: peroxidase and catalase involvement. - Ann. Bot.-London 93: 53-60, 2004a.

Fernández-García N., Martínez V., Carvajal M.: Effect of salinity on growth, mineral composition, and water relations of grafted tomato plants. - J. Plant Nutr. Soil Sci. 167: 616-622, 2004b.

Flaishman M. A., Loginovsky K., Golobowich S., Lev-Yadun S.: Arabidopsis thaliana as a model system for graft union development in homografts and heterografts. - J. Plant Growth Regul. 27: 231-239, 2008

Genty B., Briantais J.-M., Baker N.R.: The relationship between the quantum yield of photosynthetic electron transport and quenching of chlorophyll fluorescence. - Biochem. Biophys. Acta 990: 87-92, 1989.

Goldschmidt E.E.: Plant grafting: new mechanisms, evolutionary implications. - Front. Plant Sci. 5: 727, 2014.

Guidi L., Mori S., Degl'Innocenti E., Pecchia S.: Effects of ozone exposure or fungal pathogen on white lupin leaves as determined by imaging of chlorophyll $a$ fluorescence. - Plant Physiol. Bioch. 45: 851-857, 2007.

Hartmann H., Kester D., Davies F., Geneve R.: Plant Propagation. Principes and Practices, $7^{\text {th }}$ ed. Pp. 849. Prentice Hall, New Jersey 2002.

Hudina M., Orazem P., Jakopic J., Stampar F.: The phenolic content and its involvement in the graft incompatibility process of various pear rootstocks (Pyrus communis L.). - J. Plant Physiol. 171: 76-84, 2014.

Irisarri P., Binczycki P., Errea P. et al: Oxidative stress associated with rootstock-scion interactions in pear/quince combinations during early stages of graft development. - J. Plant Physiol. 176: $25-35,2015$.

Ives L., Brathwaite R., Barclay G. et al.: Graft compatibility of 
scotch bonnet (Capsicum chinense Jacq) with selected salttolerant solanaceous. - J. Agric. Sci. Technol. 2: 81-92, 2012.

Johkan M., Mitukuri K., Yamasaki S. et al.: Causes of defoliation and low survival rate of grafted sweet pepper plants. - Sci. Hortic.-Amsterdam 119: 103-107, 2009.

Kawaguchi M., Taji A., Backhouse D. et al.: Anatomy and physiology of graft incompatibility in solanaceous plants. $-\mathrm{J}$. Hortic. Sci. Biotech. 83: 581-588, 2008.

Martínez-Ballesta M.C., Alcaraz-López C., Muries B. et al.: Physiological aspects of rootstock-scion interactions.- Sci. Hortic.-Amsterdam 127: 112-118, 2010.

Miguel A., De la Torre F., Baixauli C. et al:: [Grafting of vegetables.] Pp. 63. Ministerio de Agricultura, Pesca y Alimentación y Fundación Rural Caja, Valencia 2007. [In Spanish]

Milien M., Renault-Spilmont A.-S., Cookson S.J. et al.: Visualization of the 3D structure of the graft union of grapevine using X-ray tomography. - Sci. Hortic.-Amsterdam 144: 130140, 2012.

Mudge K., Janick J., Scofield S., Goldschmidt E. E.: A history of grafting. - In: Janick J. (ed.): Horticultural Reviews, Vol. 35. Pp. 437-494, John Wiley \& Sons, New York 2009.

O’Brien T., McCully M.: The Study of Plant Structure: Principles and Selected Methods. Pp. 352. Melburne: Termacarphy. 1981.

Oka Y., Offenbach R., Pivonia S.: Pepper rootstock graft compatibility and response to Meloidogyne javanica and $M$. incognita. - J. Nematol. 36: 137-141, 2004.

Oquist G., Chow W.S.: On the relationship between the quantum yield of photosystem II electron transport, as determined by chlorophyll fluorescence and the quantum yield of $\mathrm{CO}_{2}-$ dependent $\mathrm{O}_{2}$ evolution. - Photosynth. Res. 33: 51-62, 1992.

Orsini F., Sanoubar R., Oztekin G.B. et al.: Improved stomatal regulation and ion partitioning boosts salt tolerance in grafted melon. - Func. Plant Biol. 40: 628-636, 2013.

Osmond C.B.: What is photoinhibition? Some insights from comparisons of shade and sun plants. - In: Baker N.R., Bowyer J.R. (ed.): Photoinhibition of Photosynthesis from Molecular Mechanisms to the Field. Pp. 1-24. Bios Sci. Publ., Oxford 1994.

Otsuka K.: Studies on nutritional physiology of grafted plants, part 2. Rootstocks-scion influences on growth and on ionic accumulation of solanaceous grafts. - Jpn. J. Soil Sci. Plant Nutr. 28: 285-289, 1957.

Oxborough K., Baker N.R.: An instrument capable of imaging chlorophyll $a$ fluorescence from intact leaves at very low irradiance and at cellular and subcellular levels of organization. - Plant Cell Environ. 20: 1473-1483, 1997.

Padgett M., Morrison J.C.: Changes in grape berry exudates during fruit development and their effect on mycelial growth of Botrytis cinerea. - J. Am. Soc. Hortic. Sci. 115: 269-273, 1990.

Penella C., Nebauer S.G., Quiñones A. et.al.: Some rootstocks improve pepper tolerance to mild salinity through ionic regulation. - Plant Sci. 230: 12-22, 2015.

Penella C., Nebauer S.G., Bautista A.S. et al.: Rootstock alleviates PEG-induced water stress in grafted pepper seedlings: Physiological responses. - J. Plant Physiol. 171: 842-851, 2014a.

Penella C., Nebauer S.G., López-Galarza S. et al.: Evaluation of some pepper genotypes as rootstocks in water stress conditions. - Hortic. Sci. 41: 192-200, 2014b.

Penella C., Nebauer S.G., San Bautista A. et al.: Improving Water Stress Resistance of Pepper through Grafting. Abstract in Innovation in Vegetable Grafting for Sustainability. $2^{\text {nd }}$ COST action FA1204 Congress. Pp. 44. Carcavelos 2014c.

Penella C., Nebauer S.G., Lopéz-Galarza S. et al.: Evaluation for salt stress tolerance of pepper genotypes to be used as rootstocks. - J. Food Agric. Environ. 11: 1101-1107, 2013.

Pina A., Errea P., Martens H.J.: Graft union formation and cellto-cell communication via plasmodesmata in compatible and incompatible stem unions of Prunus spp. - Sci. Hortic.Amsterdam 143: 144-150, 2012.

Pina A., Errea P., Schulz A., Martens H.J.: Cell-to-cell transport through plasmodesmata in tree callus cultures. - Tree Physiol. 29: 809-818, 2009.

Pina A., Errea P.: A review of new advances in mechanism of graft compatibility- incompatibility. - Sci. Hortic.-Amsterdam 106: 1-11, 2005.

Quilliam R.S., Swarbrick P.J., Scholes J.D., Rolfe S.: Imaging photosynthesis in wounded leaves of Arabidopsis thaliana. - J. Exp. Bot. 57: 55-69, 2006.

Rolfe S.A., Scholes J.D.: Chlorophyll fluorescence imaging of plant-pathogen interactions. - Protoplasma 247: 163-175, 2010.

Rouphael Y., Schwarz D., Krumbein A., Colla G.: Impact of grafting on product quality of fruit vegetables. - Sci. Hortic.Amsterdam 127: 172-179, 2010.

Ruiz J.M., Belakbir A., López-Cantarero I., Romero L.: Leafmacronutrient content and yield in grafted melon plants. A model to evaluate the influence of rootstock genotype. - Sci. Hortic.-Amsterdam 71: 227-234, 1997.

Sánchez-Rodríguez E., Romero L., Ruiz J.M.: Role of grafting in resistance to water stress in tomato plants: ammonia production and assimilation. - J. Plant Growth Regul. 32: 831-842, 2013.

Savvas D., Colla G., Rouphael Y., Schwarz D.: Amelioration of heavy metal and nutrient stress in fruit vegetables by grafting. - Sci. Hortic. 127: 156-161, 2010.

Schöning U., Kollmann R.: Phloem translocation in regenerating in vitro - heterografts of different compatibility. - J. Exp. Bot. 48: 289-295, 1997.

Schreiber U., Schliwa U., Bilger W.: Continuous recording of photochemical and non-photochemical chlorophyll fluorescence quenching with a new type of modulation fluorometer. Photosynth. Res. 10: 51-62, 1986.

Tadeo F.R., Gómez-Cadenas A., Ben-Cheikh W. et al.: Gibberellin-ethylene interaction controls radial expansion in citrus roots. - Planta 202: 370-378, 1997.

Trinchera A., Pandozy G., Rinaldi S. et al.: Graft union formation in artichoke grafting onto wild and cultivated cardoon: an anatomical study. - J. Plant Physiol. 170: 1569-1578, 2013.

Wang Y., Kollmann R.: Vascular differentiation in the graft union of in vitro grafts with different compatibility. - Structural and functional aspects. - J. Plant Physiol. 147: 521-533, 1996.

Yin H., Yan B., Sun J. et al.: Graft-union development: a delicate process that involves cell-cell communication between scion and stock for local auxin accumulation. - J. Exp. Bot. 63: 42194232,2012 